\title{
London to host ambitious research hub
}

The announcement last week that Europe's largest medicalresearch facility is to be built in central London has been largely welcomed by Britain's biomedical community, which hopes that the centre will accelerate the translational research - so beloved by policy-makers - that brings discoveries from the lab to patients. But the process has ruffled a few scientists' feathers.

Prime Minister Gordon Brown says that the government will sell a plot of land between the British Library and the international train station at St Pancras to a consortium of the Medical Research Council (MRC), Cancer Research UK (CRUK), the Wellcome Trust and University College London, for $£ 85$ million (US\$173 million). The total cost of the UK Centre for Medical Research and Innova-

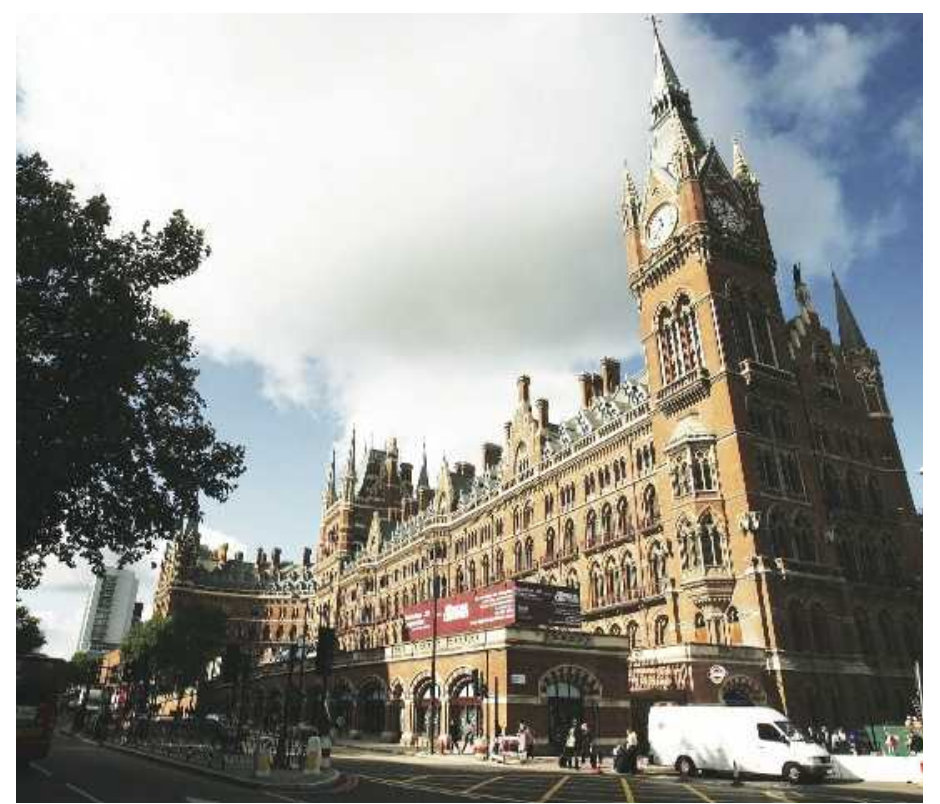

International draw: the MRC's new labs will be next to St Pancras station.

The project will face numerous hurdles. Some researchers have expressed concerns that the infusion of funding into a prestigious project with limited space could ultimately hamper some basic research already taking place. And choosing to site the centre - which will include the largest animal-research laboratory in Europe and a category- 4 virus containment laboratory - next to an international transport hub has sparked biosafety concerns.

Unease about potential staff reductions and shelving of core research has been particularly pronounced at the MRC's largest research body, the National Institute for Medical Research (NIMR), which will account for the bulk of the MRC's contribution to the new centre. The NIMR's 750 scientists and staff have already experienced tion, including purchase of the land, is pegged at more than $£ 500$ million. The MRC and CRUK are expected to shoulder the bulk of the cost, and the Wellcome Trust has committed $£ 100$ million to the project. The centre, which is expected to open in 2013, will employ up to 1,500 researchers and support staff.

It aims to compete with other global multidisciplinary scientific-research collaborations such as Biopolis in Singapore, the Allston Initiative at Harvard University and the Science-based Zizhu Industrial Park in Shanghai. "Being in central London, right alongside main teaching hospitals and main offices for clinical

research, is a much better location for translational research," MRC head Leszek Borysiewicz told Nature. "There is every opportunity for scientists to translate their work with the most appropriate clinical partners when they are that close to each other."

Details of the research projects and teams that will be transferred to the centre remain scarce. Nobel laureate Paul Nurse, who is president of Rockefeller University in New York and CRUK's former director, will head an independent science-planning committee to determine the shape and direction of the centre's work and the facilities needed to carry it out. nearly four years of debate within the MRC over its plans to move the institute from its current 19-hectare site in Mill Hill, northwest London, to central London. An earlier plan to move the institute to a site next to Euston Station in conjunction with University College London was ditched in March after the proposal faced scathing criticism from a key committee in the House of Commons that had held hearings on the plan.

NIMR staffers have previously expressed concerns that the 1.4-hectare site at St Pancras would have insufficient space for the institute's current facilities. Scientists have also criticized

\section{Nuclear-reactor closure hits cancer tests}

Hospitals across North America have been forced to cancel tests for cancer and heart disease because the unexpected closure of a Canadian nuclear reactor has led to a sudden shortage of medical isotopes.

The 50-year-old National Research Universal (NRU) reactor located in Chalk River, Ontario, was shut down on 18 November for scheduled maintenance and was due back online by mid-December. But Atomic Energy Canada, which owns and operates the facility, extended the outage to install safety-related equipment, including upgrades to the reactor cooling pumps. The reactor supplies about $60 \%$ of the molybdenum isotopes used in medical applications globally, including molybdenum-99, which decays into technetium-99m and is used in about 16 million nuclear medicine procedures annually in the United States.

"It's a disaster for patients," says Sandy McEwan, president of the Society of Nuclear Medicine. North American hospitals now have $20-30 \%$ of the medical isotopes they require, he says.
Hospitals use a generator to extract technetium-99m from a source of decaying molybdenum-99. A technetium-99m isotope has a useful life of about one week, but can be stretched to two. MDS Nordion, an Ottawa-based life-sciences firm and molybdenum supplier to Bristol-Myers Squibb Medical Imaging, says it expects shortages of the radioisotope until midJanuary. Molybdenum-99 has a half-life of 66 hours and cannot be stockpiled. Reactors in Australia, South Africa and Brussels also produce molybdenum- 99 . The shortage has 
MRC executives for poor internal communication over the course of the discussions on the institute's fate, and say that the continuing uncertainty over how much of the NIMR will be transferred to the new research centre is taking a toll on morale. "It's going to be a very difficult management process to keep people happy," says Robin Lovell-Badge, head of stem-cell biology and developmental genetics at the NIMR. "We are very nervous about it. Of course we can see the advantages and we want to be optimistic, but a lot of people at the institute just don't trust the MRC because of its past history."

\section{Translational medicine}

Borysiewicz says that Nurse's committee is expected to draw up broad outlines of the new centre's scientific mission over the weeks to come, and he adds that NIMR researchers will be represented on the committee. "It may be five or six years before the new site is ready," he says. "It is the MRC's intention to support the science at the NIMR during that period."

Others think that the move will help their work. Neil McDonald, a structural biologist at CRUK, notes that his current central London lab needs major refurbishment, and says that the new centre was being viewed positively by CRUK's several hundred researchers. "The advantage of a big research institute, and the synergies involved, are not just economies of scale but accessibility to facilities that you wouldn't be able to afford at a smaller institute," he says. "If you are in the same building and you see people in the canteen every day, it promotes collaborations and interactions, not just between research scientists but between scientists and clinicians."

The proposed centre still needs planning permission to go ahead, but with Brown's backing, it is likely to succeed.

Andrea Chipman

reignited a discussion over securing the US supply of medical isotopes by building a reactor in the United States.

The NRU reactor was to be decommissioned in 2005, but its operating licence was extended until problems with two replacement reactors - MAPLE 1 and 2 - could be solved. The two MAPLE reactors and a processing facility were designed to supply the entire global demand for molybdenum-99, iodine-131, iodine125 and xenon-133. In June, Atomic Energy Canada said that it expected MAPLE 1 and the processing facility to be in service by October 2008, and MAPLE 2 by

October 2009.

Hannah Hoag

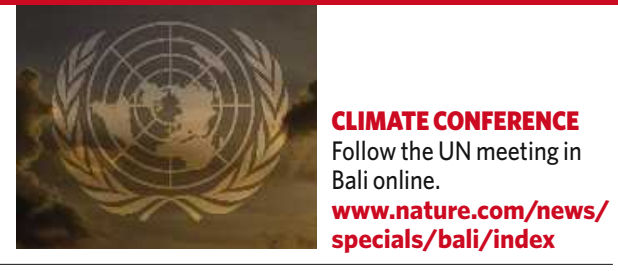

Enigmatic clouds illuminated

\section{SAN FRANCISCO}

New findings from the edge of space are unmasking Earth's highest clouds.

A NASA satellite called Aeronomy of Ice in the Mesosphere (AIM) is sending back the first detailed information on the 'noctilucent' clouds, which shimmer overhead just after sundown at high latitudes, where they reflect the below-horizon Sun.

The AIM data reveal that the clouds are ten times brighter than previously thought, and form at a broader range of altitudes. Although it had been thought that the clouds were limited to a single altitude band of 82 kilometres, in fact they can form at anywhere between 79 and 90 kilometres. AIM has also shown that small patchy groupings of cloud can grow dramatically with even a tiny fall in temperature.

"This all yields critical information to determine why these clouds form and vary," says atmospheric scientist James Russell of Hampton University in
Virginia, AIM's principal investigator.

Noctilucent clouds form when water vapour condenses onto 'seed' particles in the mesosphere, the layer of the atmosphere that extends from about 50 to 80 kilometres up. They have appeared more frequently and at lower latitudes in recent years, perhaps as a result of rising concentrations of greenhouse gases.

\section{"This all yields critical information to determine why these clouds form and vary."}

Increasing amounts of methane can result in more water vapour at the relevant altitudes, and rising levels of carbon dioxide cause temperatures in the mesosphere to drop, enhancing the conditions in which the clouds can occur. Noctilucent clouds typically form at temperatures of between -134 and $-148^{\circ} \mathrm{C}$. The new details from AIM, reported on 10 December at a meeting of the American Geophysical Union in San Francisco, California, include strange 'ice rings' that appear in some of the clouds, says project co-investigator Gary Thomas of the University of Colorado in Boulder.

These crescent-shaped blobs may be caused by atmospheric disturbances that propagate upwards from near Earth's surface - a phenomenon not seen before. "If true, it opens up an entirely new mechanism we had not thought of before this mission was launched," says Russell.

AIM's photographs are far more detailed than earlier studies, with a resolution of 5 kilometres. "The detail is so much richer with AIM," says Matt DeLand of Science Systems and Applications, Inc. in Lanham, Maryland, who is not involved with the mission but works on other satellite data. "It's fascinating stuff."

The first AIM data came from noctilucent clouds over the Arctic. The mission is currently gathering data on clouds in the Southern Hemisphere.

Alexandra Witze

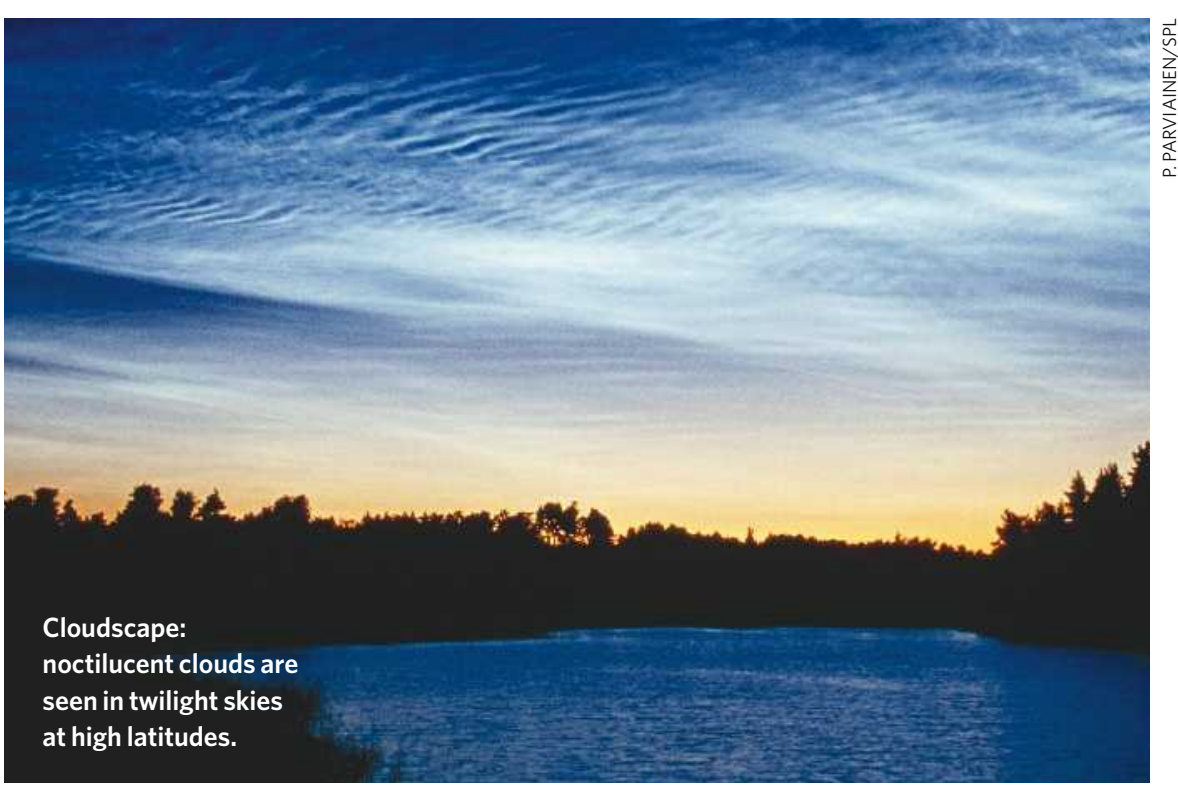

